\title{
Spousal Violence in Rural Nepal: Prevalence and Risk Factors
}

Manusha Paudel (M. Phil.)*

\begin{abstract}
Spousal violence is a major public health phenomenon. It is a hidden issue in Nepal especially in rural areas. The objective of this study is to explore the prevalence and associated risk factors of spousal violence in rural Nepal. For this study, the data has been imported from Nepal Demographic and Health Survey (NDHS), 2016. This study is confined in 1510 married women from rural Nepal. Bivariate analysis and logistic regression has been applied to examine the association between variables. Study found that more than half of the respondents were 25 to 34 years aged and the overwhelming majority were (87\%) Hindu. Study showed that half of the respondents had no education while 19 percent of respondents' husbands had no education. More than a fifth (24\%), more than a tenth (13\%) and about a tenth (8\%) had ever experienced physical, emotional and sexual violence respectively. Four in one (28\%) women experienced at least one form of violence while 3 percent experienced all three forms of violence. Education of women, education of husbands and consumption of alcohol were highly associated with spousal violence. Women who had no education were 1.7 times more likely to experience violence than higher education. Likewise, other variables for example, age at first marriage, husbands' education, consumption of alcohol and own financial account were also associating factors of spousal violence in rural Nepal. So that, attention should stand towards rural Nepal's education for both men and women, excessive consumption of alcohol, upgrade the level of empowerment of women to mitigate intimate partner violence.
\end{abstract}

Key words: Spousal violence, physical violence, sexual violence, emotional violence $\&$ married women.

\section{Introduction}

Spousal violence is a complex social and public health issue and it occurs in all socioeconomic, religious and cultural groups. WHO defines that it refers to any behavior within

\footnotetext{
${ }^{*}$ Ms. Paudel is a Lecturer at the Department of Population Studies, Patan Multiple Campus, TU, Lalitpur, Nepal.Email: manushapaudel@gmail.com
} 
an intimate relationship which causes psychological, sexual and physical harm to those in relationship (Butchart et al., 2010). Culturally in Nepal, the passive role of women and power imbalance between them in husbands' home create violence (MLJ, 2009; Pun, 2016; Emoy, 2017). On the other hand, because of the sensitivity of the subject, spousal violence is up till a hidden and under estimated social and health problem. It occurs in a pandemic proportion like cancer, HIV/AIDS, traffic accident in the world (Abeya et al., 2011).

Historically, during the 1990's violence against women has emerged as a focus of international attentions and concerns. This is first seen in 1993 when the UN General Assembly passed the declaration on the elimination of violence against women (UN, 1993). Then in 1994 at both the International Conference on Population and Development (ICPD) in Cairo and the 1995 Fourth World Conference on Women in Beijing, Women's organizations from around the world advocated ending gender violence as a high priority (WHO, 1999). In 1996 the 49 $9^{\text {th }}$ World Health Assembly adopted a resolution declaring domestic violence as a public health priority (WHO, 1997). In 1998, United Nations Development Fund for Women launched regional campaigns in Africa, Asia, pacific and Latin America to draw attention to the issue of violence against women globally. In 1999 the United Nations Population Fund declared violence against women a public health priority (UNFPA, 1999).

Research and practice over the last three decades indicates that spousal violence is a formidable social problem, intimate partner violence is violence committed by a spouse, boyfriend, girlfriend or other partner with whom an individual has or previously had on intimate or sexual relationship (Niaz, 2003). Globally, the Demographic and Health Survey (DHS) started to collect the information about intimate partner violence since 1990 in Colombia DHS survey and since 2000, DHS developed a standard module and methodology to collect the data on domestic violence (Hindin, 2008). In Nepal status of women in education and decision making is less than men however over the past decades progress has been made. The levels of maternal mortality, infant mortality have been improved. Regarding the issue of domestic violence, in 2008 Nepal's parliament passed the domestic violence (crime and punishment) act which criminalized domestic violence for the first time. Then, the government of Nepal developed the National gender based violence plan of action in 2010 and declared this year as the year to combat gender based violence. In Nepal, the area based studies showed that the prevalence of spousal violence is high, though the National level studies on spousal violence has conducted since 2011 in the first time by the Ministry of Health and Population, Nepal Demographic and Health Survey, 2011. This survey showed that 26 percent married women had experience at least 
one form of spousal violence during her married life. This study showed that the level of violence is high in rural area than urban area, such as 29 percent rural women experienced physical or sexual violence whereas only 25 percent urban women experienced such violence (MoHP, 2012).

The overall scenario of rural Nepal showed that, it is one step back than urban in every sustainable development indicator, such as empowerment, education, income, awareness and overall development. Intimate Partner Violence is such a variable which hinders to uplift these developmental variables. Therefore, to create the peace and the decent standard of living in rural areas we cannot bypass the study on spousal violence.

\section{Objective}

The objective of this study is to explore the prevalence and associated risk factors of spousal violence in rural Nepal.

\section{Methodology}

For this study the data had come from Nepal Demographic and Health Survey (NDHS) conducted in 2016 a nationally representative sample survey. We used publicly available dataset from the measures DHS website. Analysis was restricted to 1510 currently married women in rural Nepal who had selected for domestic violence module and interviewed. The 2016 NDHS sample was stratified and selected in two stages in rural areas and three stages in urban areas. In rural areas wards were selected as primary sampling units and households were selected from the sample primary sampling unit (PSUs). The study protocol was approved by the Nepal Health Research Council (NHRC) and the ICF Macro Institutional Review Board in Calverton, Maryland, USA. All respondents had provided verbal informed consent prior to data collection. Therefore, independent ethical approval was not required (MoHP, 2017).

The measurable outcome of the study was the experience of different forms (psychological, sexual and physical) of spousal violence a dichotomous variable. Experience between explanatory variables and experience of spousal violence was assessed via- bivariate analysis using chi-square tests and binary logistic regression was used to access the net effect of different independent variables on forms of violence. Results are considered at the significant at $\mathrm{P}<0.05$. The Statistical Package for Social Science (SPSS 20.0 for Windows) software was used to analyze the data. 


\section{Findings}

Study found that majority of the respondents (nearly two fifth) were aged 25 to 34 years while nearly one fourth were less than 25 years. An overwhelming majority of the women $(87 \%)$ were Hindus. It is found that the highest percent were janjati (32\%) and dalit (14\%) were in lowest rank. Majority of the respondents were currently married and 3 percent were widowed whereas divorced and separated were less than one percent. Study found that half of the women had no education and one fifth respondents had primary education but nearly one fourth had secondary. In the higher level the percent had less. Similarly, the data of age at first marriage prevails the typical rural area, it showed that half of the respondents had got marriage between the age of 16 to 19 years while less than one fifth had got marriage 20 years and above. Similarly, wealth index showed than more than half of the respondents were poor.

In the characteristics of respondents' husbands, one fifth had no education; it showed the higher gap in the education of husbands and wives. Furthermore, nearly, 47 percent respondents' husbands drink alcohol. In addition, nearly two fifth women have their own financial account.

Table 1: Background characteristics of respondents

\begin{tabular}{|c|c|c|}
\hline Background Characteristics & Number & Percent \\
\hline \multicolumn{3}{|l|}{ Age group of women } \\
\hline Less than 25 years & 369 & 24.4 \\
\hline $25-34$ years & 588 & 39.0 \\
\hline 35 years and above & 553 & 36.6 \\
\hline \multicolumn{3}{|l|}{ Religion } \\
\hline Hindu & 1320 & 87.4 \\
\hline Non-Hindu & 190 & 12.6 \\
\hline \multicolumn{3}{|l|}{ Ethnicity } \\
\hline Brahimin/Chhetri & 405 & 26.8 \\
\hline Janjati & 490 & 32.4 \\
\hline Dalit & 215 & 14.2 \\
\hline Others & 401 & 26.5 \\
\hline \multicolumn{3}{|l|}{ Current marital status } \\
\hline Married & 1455 & 96.3 \\
\hline
\end{tabular}




\begin{tabular}{|c|c|c|}
\hline Widowed & 40 & 2.7 \\
\hline Divorced & 2 & 0.1 \\
\hline $\begin{array}{l}\text { No longer living together/ Sep- } \\
\text { arated }\end{array}$ & 14 & 0.9 \\
\hline \multicolumn{3}{|l|}{ Education of women } \\
\hline No Education & 759 & 50.3 \\
\hline Primary & 297 & 19.7 \\
\hline Secondary & 350 & 23.2 \\
\hline Higher & 103 & 6.8 \\
\hline \multicolumn{3}{|l|}{ Age at first marriage } \\
\hline Less than 16 years & 421 & 27.9 \\
\hline 16-19 years & 761 & 50.4 \\
\hline 20 years and above & 280 & 18.5 \\
\hline Don't know & 49 & 3.2 \\
\hline \multicolumn{3}{|l|}{ Wealth index } \\
\hline Poor & 806 & 53.4 \\
\hline Middle & 352 & 23.3 \\
\hline Rich & 352 & 23.3 \\
\hline \multicolumn{3}{|l|}{ Education of husbands } \\
\hline No education & 286 & 18.9 \\
\hline Primary & 400 & 26.5 \\
\hline Secondary & 430 & 28.5 \\
\hline Higher & 337 & 22.3 \\
\hline Don't know & 57 & 3.8 \\
\hline \multicolumn{3}{|c|}{ Consumption of alcohol (husband) } \\
\hline Yes & 703 & 46.5 \\
\hline No & 807 & 53.5 \\
\hline \multicolumn{3}{|l|}{ Has an financial account (women) } \\
\hline Yes & 571 & 37.8 \\
\hline No & 939 & 62.2 \\
\hline Total & 1510 & 100 \\
\hline
\end{tabular}

Source: Nepal Demographic and Health Survey, 2016. 
Table 2 shows that a quarter women had experience physical violence. 13 percent women reported that they faced emotional violence while 8 percent women reported that they had faced sexual violence. It is found that more than a quarter $(28 \%)$ women had faced at least one form of violence (either physical or/ and emotional or/ and sexual) and 3 percent women had experienced all three forms of violence.

Table 2: Experience of different forms of violence among rural married women by their husbands in Nepal

\begin{tabular}{|c|c|c|}
\hline Experience of violence & Number & Percent \\
\hline \multicolumn{3}{|c|}{ Physical violence } \\
\hline Yes & 362 & 24.0 \\
\hline No & 1148 & 76.0 \\
\hline \multicolumn{3}{|c|}{ Sexual violence } \\
\hline Yes & 117 & 7.7 \\
\hline No & 1393 & 92.3 \\
\hline \multicolumn{3}{|c|}{ Emotional violence } \\
\hline Yes & 202 & 13.4 \\
\hline No & 1307 & 86.6 \\
\hline \multicolumn{3}{|c|}{ At least one form of violence } \\
\hline Yes & 419 & 27.7 \\
\hline No & 1091 & 72.3 \\
\hline \multicolumn{3}{|c|}{ All three forms of violence } \\
\hline Yes & 50 & 3.3 \\
\hline No & 1460 & 96.7 \\
\hline Total & 1510 & 100 \\
\hline
\end{tabular}

Source: Nepal Demographic and Health Survey, 2016.

Table 3 shows that nearly one third women had experienced at least one form of spousal violence who were aged 25 to 34 years, while who were aged less than 25 years and 35 years above had 23 percent and 27 percent spousal violence respectively. However p-value indicates that the difference is not significant. Study found that respondents' ethnicity had significantly associated $(\mathrm{p}<0.001)$ with experience of at least one form of violence among rural married women in Nepal. For instance, 28 percent women who had currently married had faced at least one form of violence while all divorced women faced this situation and the current marital status and violence has been significantly 
associated. Similarly, education of women and age of marriage were highly associated at 0.001 levels. For instance, more than one third women who had no education while one tenth women who had higher education faced at least one form of violence. In regards of husbands' characteristics, those husbands who had no education had experienced more violence (nearly half) than those who had higher education (15\%). Similarly, consumption of alcohol and form of violence are significantly associated.

Table 3: Background characteristics of rural married women according to experience of violence by their husbands in Nepal

\begin{tabular}{|l|c|c|c|}
\hline Background Characteristics & $\begin{array}{c}\text { At least one form of violence } \\
\text { (\%) }\end{array}$ & Number & p-value \\
\hline Age group of women & & & \\
\hline Less than 25 years & 22.8 & 369 & \\
\hline 25-34 years & 31.5 & 588 & \\
\hline 35 years and above & 27.1 & 553 & \\
\hline Religion & 26.7 & & \\
\hline Hindu & 35.3 & 1320 & \\
\hline Non-Hindu & & 190 & \\
\hline Ethnicity & 15.3 & 405 & $<0.001$ \\
\hline Brahimin/Chhetri & 22.7 & 490 & \\
\hline Janjati & 35.8 & 215 & \\
\hline Dalit & 42.1 & 401 & \\
\hline Others & & & \\
\hline Current marital status & 27.8 & 1455 & $<0.001$ \\
\hline Married & 9.8 & 298 & \\
\hline Widowed & 100 & 350 & \\
\hline Divorced & 71.4 & & \\
\hline $\begin{array}{l}\text { No longer living together/ } \\
\text { Separated }\end{array}$ & 28.9 & & \\
\hline Education of women & 16.6 & & \\
\hline No Education & & & \\
\hline Primary & & & \\
\hline Secondary & & & \\
\hline
\end{tabular}




\begin{tabular}{|l|c|c|c|}
\hline Higher & 9.7 & 103 & \\
\hline Age at first marriage & & & \\
\hline Less than 16 years & 33.7 & 421 & $<0.001$ \\
\hline 16-19 years & 27.7 & 761 & \\
\hline 20 years and above & 17.9 & 280 & \\
\hline Wealth index & & & \\
\hline Poor & 24.3 & 806 & $<0.05$ \\
\hline Middle & 32.9 & 353 & \\
\hline Rich & 30.7 & 352 & \\
\hline Education of husbands & & & \\
\hline No education & 44.1 & 286 & $<0.001$ \\
\hline Primary & 29.9 & 401 & \\
\hline Secondary & 25.4 & 429 & \\
\hline Higher & 14.5 & 337 & \\
\hline $\begin{array}{l}\text { Consumption of alcohol } \\
\text { (husband) }\end{array}$ & & & \\
\hline Yes & 29.5 & 703 & $<0.001$ \\
\hline No & 27.7 & 807 & \\
\hline $\begin{array}{l}\text { Has an financial account } \\
\text { (women) }\end{array}$ & 36.6 & & \\
\hline Yes & 20.1 & & \\
\hline No & & & \\
\hline Total & & & \\
\hline & & & \\
\hline
\end{tabular}

Source: Nepal Demographic and Health Survey, 2016.

This study had used binary logistic regression model to show the effects of independent variables on dependent variable. In this model, had included different socio-demographic and economic variables as independent variables and experienced at least one form of spousal violence as a dependent variable. Table 4 contains the odd ratio of logistic regression coefficient and 95 percent confidence interval for odd ratios for each category. From the fitted model shows that women who had aged 25-34 years had more likely $(\mathrm{OR}=1.259)$ to experience violence from their husband. On the other hand, women who were Hindu, had less likely $(\mathrm{OR}=0.700)$ to experience spousal. 
Likewise, those women who got primary education only had 1.7 times more like to experience spousal violence than who had got higher education. Similarly, those women who got married before 16 years were 1.7 times more likely to experience violence than who got married 20 years and after. Women whose husbands had no education were 2.9 times more likely to experience spousal violence than women whose husbands had higher education. Similarly, women whose husband did not take alcohol had less likely to experience violence than who had taken alcohol. In addition, women who have not own financial account had more likely $(\mathrm{OR}=1.04)$ to experience violence by their husbands.

Table 4: Odd Ratio (OR) and 95\% Confidence Interval (CI) for having experienced of violence from their husbands among rural married women in Nepal

\begin{tabular}{|l|c|c|c|}
\hline Predictors & Odd Ratio & P-Value & $\begin{array}{c}\text { 95\% Confidence Interval } \\
\text { (CI) }\end{array}$ \\
\cline { 1 - 3 } Age group of women & 0.934 & 0.738 & $0.62-1.39$ \\
\hline Less than 25 years & 1.259 & 0.132 & $0.93-1.69$ \\
\hline 25-34 years & 1 & & \\
\hline Religion & & & $0.48-1.02$ \\
\hline Hindu & 0.700 & 0.063 & \\
\hline Non-Hindu & 1 & & $0.21-0.50$ \\
\hline Ethnicity & & & $0.24-0.52$ \\
\hline Brahimin/Chhetri & 0.325 & 0.001 & $0.32-0.74$ \\
\hline Janjati & 0.359 & 0.001 & \\
\hline Dalit & 0.489 & 0.001 & $0.77-3.74$ \\
\hline Others & 1 & & $0.65-3.18$ \\
\hline Education of women & & & $0.53-2.45$ \\
\hline No Education & 1.707 & 0.182 & \\
\hline Primary & 1.444 & 0.363 & \\
\hline Secondary & 1.140 & 0.738 & \\
\hline Higher & 1 & & $0.63-1.13$ \\
\hline Age at first marriage & & & \\
\hline Less than 16 years & 1.706 & 0.277 & \\
\hline $16-19$ years & 1.418 & 0.133 & \\
\hline 20 years and above & 1 & & \\
\hline
\end{tabular}




\begin{tabular}{|l|c|c|c|}
\hline Wealth index & & & \\
\hline Poor & 0.672 & 0.034 & $0.46-0.97$ \\
\hline Middle & 0.808 & 0.258 & $0.55-1.17$ \\
\hline Rich & 1 & & \\
\hline Education of husbands & & & \\
\hline No education & 2.900 & 0.001 & $1.78-4.71$ \\
\hline Primary & 1.800 & 0.011 & $1.14-2.82$ \\
\hline Secondary & 1.513 & 0.055 & $0.99-2.30$ \\
\hline Higher & 1 & & \\
\hline $\begin{array}{l}\text { Consumption of alcohol } \\
\text { (husband) }\end{array}$ & & & $0.24-0.43$ \\
\hline No & 0.324 & 0.001 & \\
\hline Yes & 1 & & \\
\hline $\begin{array}{l}\text { Has an financial account } \\
\text { (women) }\end{array}$ & & & \\
\hline No & 1.048 & 0.742 & \\
\hline Yes & 1 & & \\
\hline
\end{tabular}

Source: Nepal Demographic and Health Survey, 2016.

\section{Discussion}

This study has tried to explore the prevalence and risk factors of spousal violence in rural Nepal. The present study shows that spousal violence is common among rural women and it affects the overall development in rural areas and indicates a need for an effective program on spousal violence issue. In a survey of reproductive-aged women in rural Bangladesh, 47 per cent of the women reported having ever been beaten by their husbands, 19 per cent within the previous year (Schuler, 1996).

This study found that physical violence is high (24\%), than emotional and sexual violence. In every one in four women has faced physical violence. A study of physical violence in slum areas of Kathmandu valley showed the highest prevalence $(65 \%)$ during her life time (Paudel, 2019). Similarly a study on violence in Africa found that physical violence is highest and almost half of the countries' lifetime prevalence is over 40 percent (UN, 2015). 
The bivariate analysis shows some variables such as age, religion, ethnicity, age at first marriage, education, consumption of alcohol and financial account, which are important in explaining spousal violence. Bivariate analysis shows the significant association between dependent and independent variables while multivariate analysis support the findings of bivariate analysis. This study has found that women who were age 25-34 had experienced high IPV than early and later age groups. While, in Europe women in youngest group had high prevalence of spousal violence than older aged (UN, 2015). The WHO multi country study reveals that younger women, especially those age (15-19 years) are at higher risk of experiencing spousal violence (Erulkar, 2013). In Nepal, a study conducted in young couple found that 50 percent young married women falls on sexual violence because of lack of education (Puri, 2008).

This study found that women who had no education were 1.7 times more likely to experience violence from their husband. Similar another study which had done at rural Nepal in 2011, found that women's educational deprivation is the most influential risk factor of spousal violence in Nepal (Lamichhane et al., 2011). In addition a study in India showed that women which have lower level of education had higher risk of spousal violence (Akerson et al., 2008). That type of situation is common in most of developing countries (Niaz, 2003; Hajjar, 2006).

Result of this study found that those women who had got married before 16 years were more likely to experience violence than who got married 20 years and above. Similarly a study of UNICEF in nine countries, found that girls who were married before 18 years were more likely to experience domestic violence than peers who married later. Another study in India found that early marriage is associated with low involvement in the decision to marry fewer interactions with one's spouse and elevated risk of intimate partner violence (Erulkar, 2013). On the other hand, study found that women, who were poor wealth index, had less likely to experience spousal violence than rich. But most of the literatures found that who have poor economic status have higher risk of violence (MoHP, 2012; Puri, 2008). Similarly another study found that, lower-class men often have lack of power and authority in their work environments; they may construct rigid, aggressive models of masculinity in the home (Messerschmidt, 1993) and literature hints that besides level of income, husband's educational status determines the level of higher and lower class. This study found that those women, whose husbands had no education, had 2.9 times more likely to experience spousal violence than who had higher education. Similarly, a WHO multi country study on Women's health and domestic violence showed that the highly educated group of husbands had lower odds ratio's for spousal violence in 10 out of 14 Sites (Abramsky, 2011). This study found that, husbands who did not 
consume alcohol were less likely to experience spousal violence. Similarly, a Kenyan DHS report found that, alcohol use by the male partner was associated with women's ever experiencing either physical or sexual abuse (Kimuna, 2008). In Nepal, a study also reveals that respondents whose husband consumed alcohol were more likely to experience sexual coercion than those whose husband did not consume alcohol (Adhikari, 2009). Another study in Nepal found that nearly 40 per cent women fall on sexual violence whose husband use alcohol (Puri , 2008). Lastly, results showed that, women who had not financial account were more likely to experience violence than who had financial account. Literatures also showed that economic autonomy helps to reduce the violence (Ellsberg, 2015).

\section{Conclusion}

This study found that spousal violence of married women in rural Nepal is prevalent. Physical violence is high than others. Findings of the study help to know the factors, which are important effect on spousal violence. This study highlights that age at marriage, women's and husbands' education, consumption of alcohol and own financial account are important variables to decrease the level of spousal violence in rural areas. Intervention should focus towards upgrade the level of education on both husbands and wives, raise the awareness on early age marriage, consumption of alcohol; and move towards women's financial inclusion to break the cycle of spousal violence and overall development of rural area in Nepal.

\section{References}

Abeya, G. S., Afework, F. M., \& Yalew, W. A. (2011). Intimate partner violence against women in western Ethiopia: Prevalence, patterns and associated factors. https:// www.biomedcentral.com/14/1-24/58/11/9/3.

Abramsky, T., Watts, C. H., Garcia-Moreno, C., Devries, K., Kiss, L., Ellsberg, M., Jansen, H. A., \& Heise, L. (2011). What factors are associated with recent intimate partner violence? Findings from the WHO multi-country study on women's health and domestic violence. BMC Public Health, 11(109).

Ackerson, L. K. I., Kawachi, B., \& Subramanian, S. V. (2008). Effects of individual and proximate educational context on intimate partner violence. A population based study of women in India. American Journal of Public Health, 98(3), 507-14.

Adhikari, R., \& Tamang, J. (2009). Sexual coercion of married women in Nepal. BMC Women's Health 10(31). https://doi.org/10.1186/1472-6874-10-31 
Butchart, A., Garcia-Moreno, C., \& Mikton, C. (2010). Preventing intimate partner and sexual violence against women: Taking action and generating evidence. World Health Organization, Geneva

Ellsberg, M., Arango, D. J., Morton, M., Gennari, F., Kiplesund, S., \& Contreras, M. (2015). Prevention of violence against women and girls: What does the evidence say? 385(9977), 1555-66. https://doi.org/10.1016/S0140-6736(14)61703-7 PMID: 25467575

Emery, C. R., Thapa, S., \& Wu, S. (2017). Power and control in Kathmandu: A comparison of attempted power, actual power, and achieved power. Violence against Women, 23(4), 482-502.

Erulkar, A. (2013). Early marriage, marital relations and intimate partner violence in Ethiopia. International Perspectives on Sexual and Reproductive Health. Guttmacher Institute, 39(1), 6-13. https://www.jstor.org/stable/23408822 on 17/03/2014.

Hajjar, L. (2006). Religion, state power, and domestic violence in Muslim societies: A framework for comparative analysis. Law and Social Inquiry, 29(1).

Hindin, M. J., Sunita, K., \& Donna, L. A. (2008). Intimate partner violence among couples in 10 DHS countries: Predictors and health outcomes. DHS Analytical Studies, (18). Calverton, Maryland, USA.

Kimuna, S. R., \& Djamba, Y. K. (2008). Gender based violence: Correlates of physical and sexual wife abuse in Kenya. Journal of Family Violence, 23 (5), 333-42.

Lamichhane, P., Puri, M., Tamang, J., \& Dulal, B. (2011). Women's status and violence against young married women in rural Nepal. BMC Women's Health, 11(19). https://doi.org/10.1186/1472-6874-11-19.

Messerschmidt, J. W. (1993). Masculinities and crime: Critique and reconceptualization of theory: Laham, MD: Rowmah and Littlefield.

Ministry of Health and Population (MoHP). (2017). Nepal demographic and health survey 2016. Kathmandu: Ministry of Health and Population New ERA and IFC International, Nepal.

Ministry of Health and Population (MoHP). (2012). Nepal demographic and health survey 2011. Kathmandu: Ministry of Health and Population New ERA and IFC International, Nepal.

Ministry of Law and Justice (MoLJ). (2009). Domestic violence (offence and punishment) 
act, 2009. Kathmandu, Nepal.

Niaz, U. (2003). Violence against women in south Asian countries. Women's Mental Health, 6(3), 173-184.

Paudel, M. (2019). Prevalence and factors associated with physical intimate partner violence in slum areas of Kathmandu valley. Electronic Research Journal of Social Sciences and Humanities, 1(4).

Pun, K. D., Infanti, J. J., Koju, R., Schei, B., \& Darj, E. (2016). Community perceptions on domestic violence against pregnant women in Nepal: A qualitative study. Global Health Action, 9(1). https://doi.org/10.3402/GHA.V9.31964

Puri, M. (2008). Exploring the nature and reasons associated with sexual violence within marriage among young couples in Nepal. Annual meeting of PPA. Sheraton New Orleans, USA.

Schuler, S. R. (1996). Credit programmes, patriarchy men's violence against women in rural Bangladesh. Social Science Medicine, 4 (12), 1729-1742.

United Nations Population Fund (UNFPA). (1999). Violence against women. New York.

United Nations (UN). (1993). Declaration on the elimination of violence against women. General Assembly. United Nations.

United Nations (UN). (2015). Violence against women. The World's women. Worlds Women 2015 chapter6 t.pdf (un.org)

World Health Organization (WHO). (1999). Putting women's safety first: Ethical and safety recommendations for research on domestic violence against women, $\mathrm{WHO} /$ EIP/GPE/99.2, Geneva.

World Health Organization (WHO). (1997). Violence against women: A priority health issue. WHO/FRH/WHD/97.8, Geneva. 